\title{
Pre-yield tensile set of a semi-crystalline polymer, its blend and composite
}

\author{
W. C. J. Zuiderduin · J. Huétink · R. J. Gaymans
}

Received: 6 June 2006/Accepted: 30 August 2006/Published online: 9 April 2007

(C) Springer Science+Business Media, LLC 2007

\begin{abstract}
Tensile set was studied at low strains on polypropylene, aliphatic polyketone, rubber toughened blends and $\mathrm{CaCO}_{3}$ particle toughened composites. The rubber in the rubber toughened blends had a particle size of $0.7 \mu \mathrm{m}$. The $\mathrm{CaCO}_{3}$ particles had a size of $0.7 \mu \mathrm{m}$ and had been coated with stearic acid. Step-cyclic loading was applied in $1 \%$ strain incrementals at a strain rate of $10^{-2} \mathrm{~s}^{-1}$. The maximum strain applied was $20 \%$. The temperature of the test bar was studied with an infra-red camera. Pre-yield deformation is normally assumed to take place in a nonlinear elastic manner. However, for polypropylene and polyketone elastoplastic deformation starts at low strains. For PP the onset of tensile set is at very low strains and increases with strain. The tensile set at the yield point was only $50 \%$ and at the drawing strain $100 \%$. Polyketone had a similar tensile set development but shifted to slightly higher strains. Here too the tensile set at the yield point was about $50 \%$ and at the drawing strain $100 \%$. The temperature of the non yielded material was found to rise in polyketone a $7{ }^{\circ} \mathrm{C}$.

The rubber toughened blends had at low strains a higher tensile set, but after the yield strain the set was similar to the base polymer. At 5\% strain the tensile set increased with rubber content. The sub micron $\mathrm{CaCO}_{3}$ particle toughened composites increased the tensile set too. The
\end{abstract}

W. C. J. Zuiderduin · J. Huétink · R. J. Gaymans ( $₫)$ University of Twente, P. O. Box 217, 7500 AE Enschede, The Netherlands

e-mail: r.j.gaymans@utwente.nl

Present Address:

W. C. J. Zuiderduin

Artecs BV, Enschede, The Netherlands tensile set is a simple technique for studying the pre-yield behaviour of multi phase systems.

\section{Introduction}

The mechanical behaviour of polymers strongly depends on parameters like temperature and strain rate and typically for this is the yield strength [1]. The yield point is conventionally determined, by the Considére's construction [2], at the point of maximum stress in the nominal stress strain curve. It is generally considered that below the yield strain the deformation is nonlinear elastic [3] and at the yield point the polymer starts to deform plastically. The plastic deformation is usually by shear yielding. Semicrystalline polymers have a two phase morphology and the plastic deformation invariably takes place in an inhomogeneous manner. The yielding in semi crystalline polymers is very often accompanied by necking with an appreciable temperature rise [4-8]. For PE and PP it has been shown that the assumption that below the yield strain that the deformation in tensile is just nonlinear elastic, it too simple [9-12]. In cyclic deformation tests at low strains considerable tensile set was observed. This deformation has been called elastoplastic deformation and it is strain controlled. It is thought that this deformation is due to transformations in the amorphous phase and by crystalline slip processes. If at low strains plastic deformation is taking place than the sample temperature should increase.

In toughened blends in the pre-yield strain region, cavitation of the rubber takes place. On cavitation of the rubber particles the yield strain is not changed but the yield stress is considerably lowered [7,13]. As a consequence of this cavitation excessive shear yielding can take place. Interesting is to study whether in presence of rubber particles the pre-yield tensile set deformation is changed. 
New is the toughening by sub micron sized rigid particles [14-17]. The toughening mechanism here is the delamination of the rigid particles [15-17]. This toughening mechanism works well at low loadings $(>20 \mathrm{vol} \%)$ but as yet not at high loadings $[16,17]$. These composites have an increased modulus however their yield strength is considerable lowered. Interesting is to study whether in delamination of the submicron particles change the tensile set deformation in the pre-yield region.

In this paper the tensile set is studied in step-cyclic loading with $1 \%$ strain steps up to $20 \%$ strain. The materials studied are polypropylene, an aliphatic polyketone, a toughened blend of aliphatic polyketone and a toughened composite of aliphatic polyketone. The aliphatic polyketone is an interesting semi-crystalline polymer, similar in behaviour to PP however with a higher yield stress and a higher yield strain.

\section{Experimental}

\section{Materials}

Polypropylene, Vestolen P7000, with an MFI at $190{ }^{\circ} \mathrm{C}$ of $2.4 \mathrm{dg} / \mathrm{min}$, a modulus of $1,500 \mathrm{MPa}$, a yield stress of $34 \mathrm{MPa}$, a yield strain of $9 \%$ and a crystallinity of $45 \%$, was kindly supplied by DSM.

Aliphatic polyketone (aPK), Carilon P1000, had a modulus of, 1,850 MPa, a yield stress of $65 \mathrm{MPa}$, and a yield strain of $13 \%$, was kindly supplied by SHELL Research and Technology Centre Amsterdam (SRTCA). This is an ethyleneketone-propyleneketone copolymer, polymerised from ethylene, propylene $(6 \mathrm{~mol} \%)$ and carbon monoxide. The propylene ketone is to lower the melting temperature (Fig. 1).

The aPK has a glass transition temperature of approximately $15^{\circ} \mathrm{C}$ and a melting temperature of $225^{\circ} \mathrm{C}$ with a crystallinity of $35 \%$.

Blends of this aPK and $0.7 \mu \mathrm{m}$ rubber particles have been described [13]. Rubber are in the form of core shell particles with polybutadiene core and SAN shell (Blendex 338, from GE Plastics). The aPK- $\mathrm{CaCO}_{3}$ composites used, were made with precipitated $\mathrm{CaCO}_{3}$ particles with a

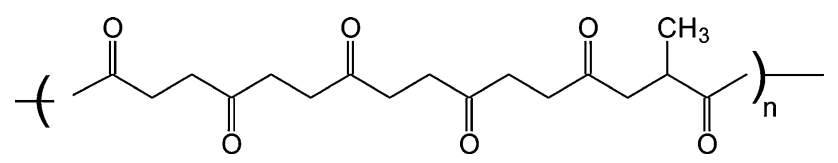

Fig. 1 Structure of aliphatic polyketone based on ethylene-ketone and propylene-ketone particle size of $0.7 \mathrm{~mm}$ and that had a stearic acid coating (Superflex from Mineral Technologies) [17].

Specimen preparation

Dumbbell shaped test samples, $4 \mathrm{~mm}$ thick, were obtained by injection moulding using an Arburg Allrounder 221-55250 injection moulding machine. The barrel had a flat temperature profile with an injection pressure of 55 bar, holding pressure was kept at 45 bar and the total cycle time was approximately $22 \mathrm{~s}$. For PP the barrel had a temperature of $200{ }^{\circ} \mathrm{C}$ and a mould temperature of $80{ }^{\circ} \mathrm{C}$. The aPK materials had a barrel temperature of $240{ }^{\circ} \mathrm{C}$ and a mould temperature of $70{ }^{\circ} \mathrm{C}$.

\section{Conditioning}

The test bars were dried at $80{ }^{\circ} \mathrm{C}$ under vacuum for $15 \mathrm{~h}$, and kept under vacuum at room temperature after this drying step. Because of the physical ageing behaviour of polyketone, the aPK test samples were every 10th day heated to $80{ }^{\circ} \mathrm{C}$ for half an hour to rejuvenate the physical ageing. After this treatment the test bars were cooled down in a controlled manner in the oven and kept under vacuum. These test samples were not used in the first 2 days after a heat treatment since the physical ageing process is very fast in this period.

\section{Tensile tests}

Normal tensile tests were conducted on dumbbell shaped specimens with a Zwick tensile Z02 tester. Test speed was $60 \mathrm{~mm} / \mathrm{min}$, which means a strain rate of $10^{-2} \mathrm{~s}^{-1}$. The strain was monitored with extensometers attached on the specimen. Standard engineering curves were obtained, the modulus was determined in the strain regime of $0.1-0.25 \%$ strain, the yield stress was taken at the first point were $\mathrm{d} \varepsilon /$ $\mathrm{d} \sigma=0$.

\section{Step-Cycle Testing}

Step-Cycle Testing experiments were conducted on a Zwick tensile tester type Z02, equipped with an extensometer. Staircase loading cycles were performed with cycles of $1 \%$ strain at a strain rate of $10^{-2} \mathrm{~s}^{-1}$. The cycles followed each other directly. After each cycle the tensile set of that cycle was calculated.

\section{Infrared thermography}

The temperature rise during fracture of specimens of thickness $4 \mathrm{~mm}$ was monitored using an infrared camera as specified elsewhere [8]. 


\section{Results and discussion}

In studying the temperature development during a tensile test a warming of the sample in the unnecked region was observed, suggesting a plastic deformation. Tensile set experiments were conducted to get more insight in this.

Pre-yield deformation

Studying the temperature development in a tensile test with an infrared camera one sees a temperature rise in the neck but also in the unnecked region (Fig. 2). In the unnecked region the temperature increase was for aPK about $7{ }^{\circ} \mathrm{C}$, which indicates that in the nonyielded unnecked region some plastic deformation has taking place. To study this pre-yield behaviour low strain step-cyclic curves were recorded, whereby in each subsequent cycle the strain was increased $1 \%$ (Fig. 3).

There was no standing time between the cycles and for each cycle the set (relative plastic strain) was determined. This cyclic test was carried out on PP and on aPK (Fig. 4).

The tensile set (TS) increases steadily with strain. At the yield strain for PP at $9 \%$ and aPK at $13 \%$, the TS is about $50 \%$ and a small transition is apparent. A $100 \%$ tensile set

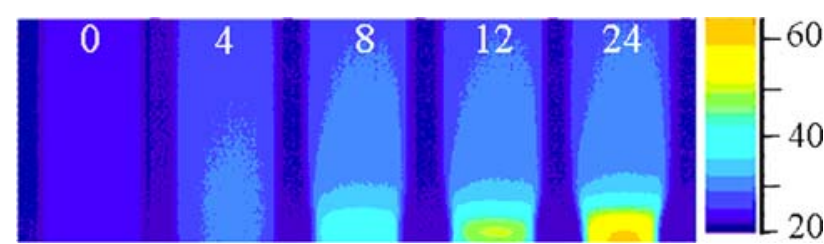

Fig. 2 Infra Red temperature measurements during a tensile test on aPK at different strains at a strain rate $10^{-2} \mathrm{~s}^{-1}$

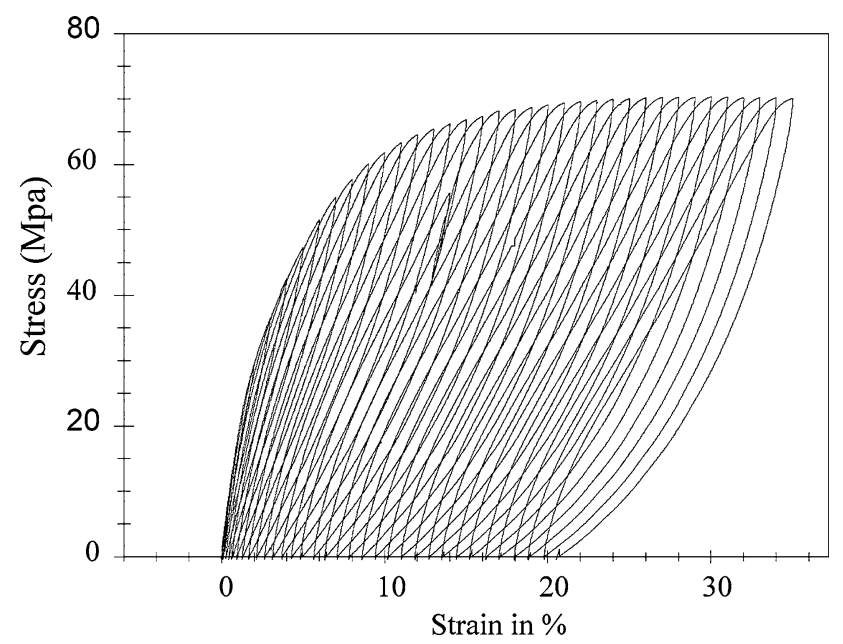

Fig. 3 Step-Cyclic tensile curves with $1 \%$ strain steps of aliphatic polyketone

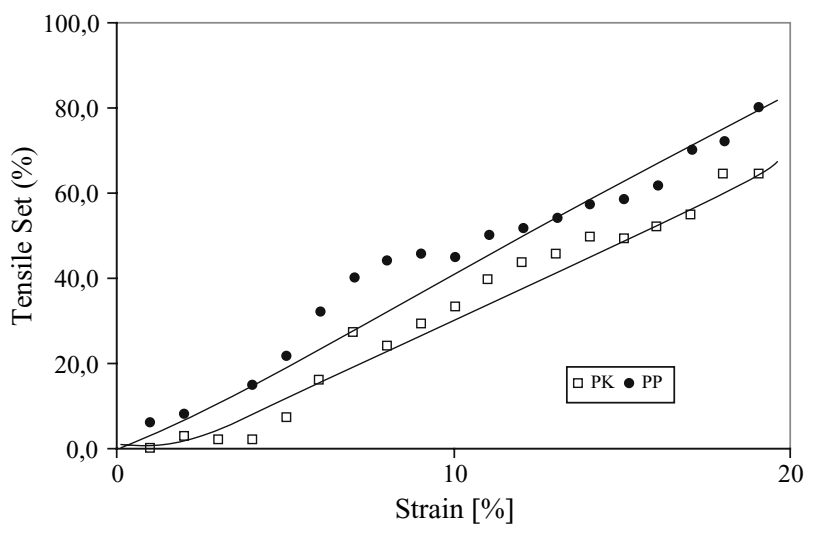

Fig. 4 Tensile Set as function of strain: $\bullet$, PP; $\square$, aPK

is reacted for $\mathrm{PP}$ at $22 \%$ and aPK at $34 \%$ strain and this is after the neck was fully developed. The differences tensile set between PP and aPK are small, the aPK has a higher yield and higher draw strains. The average tensile set once the sample has formed a neck is about $50 \%$. The observed temperature increase in the unnecked part of the sample (Fig. 1) suggests that the deformation in the pre-yield region is elastoplastic. The tensile set values below the yield point are remarkable high but at the yield point not very high. Only at the drawing strain the deformation becomes fully plastic.

It is commonly assumed that below the yield point the deformation is elastic and above the yield threshold all the deformation is plastic. It is shown here that both assumptions are for the tensile test too simple. The tensile set is continuously rising from very small strains up to the where the drawing starts and at the yield point only a small change in tensile set is observed. From this it is clear that there is no real transition at the yield point. As the tensile set is accompanied with a temperature rise of the sample a plastic deformation is taking place. The plastic deformation can be due to the deformation of the crystalline domains and/or the amorphous phase [9-12].

The tensile set was also studied on a blend with an elastomeric modifier. The function of the rubber is to cavitate and thereby to relieve the volume strain. The cavitation of the rubber is taking place before the yield strain $[13,18]$. With increasing rubber content the yield stress is considerably lowered, but the yield strain is not altered $[7,13]$. The cavitation, can be measured using the stress whitening by a laser transmission measurements. The aPK-rubber blend had an onset of cavitation at $4 \%$ strain and this was independent of rubber content. The TS of aPK-rubber blends as function of strain increases with rubber content is studied (Fig. 5).

The TS of the blends increases with rubber content and this particular up to a $10 \%$ strain. The Increased TS suggests that on cavitation of the rubber, the matrix around the 


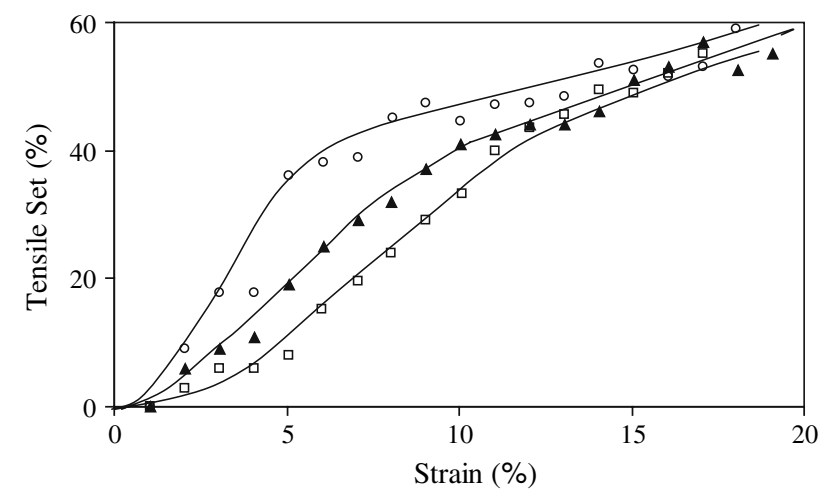

Fig. 5 Tensile set as function of strain of aPK-rubber blends: $\square$, aPK; $\boldsymbol{\Delta}, 24$ vol\% rubber; $\bigcirc, 47$ vol\% rubber

cavitated particles is locally extra deformed and the more rubber is present the stronger the effect is. Remarkable is that above a strain of $10 \%$ the blends behave similar to the homo polymer. Thus the special effects of the blends are at low strains, well below the yield strain of $13 \%$ and near the onset of cavitation (4\%) as measured by the stress whitening.

As the TS values increases with rubber content this suggest that the amount of matrix material which is affected by the cavitation process is increased with rubber content.

Polymers can also be toughened by sub micron size rigid particles [14-17]. The function of the rigid particles is to delaminate and in that way to relieve the volume strain. aPK is toughened with sub micron size $\mathrm{CaCO}_{3}$ particles $(0.7 \mu \mathrm{m})$. The particle toughening is effective at particle contents up to $16 \mathrm{vol} \%$, however, not at higher contents $[16,17]$. With increasing particle content the modulus increases but the yield stress decreases. The higher modulus indicates that that at low strains $(<1 \%)$ the particles are still bonded. The lower yield stress suggests that at these strains the particles are debonded. Debonding of the particles is thus taking place below the yield strain. The lowering of the yield stress is so strong that it is assumed that at the yield stress most particles have debonded. As the aPK- $-\mathrm{CaCO}_{3}$ samples are very white materials a stress whitening could not be observed. At lower $\mathrm{CaCO}_{3}$ contents the toughening effect of sub micron sized $\mathrm{CaCO}_{3}$ particles is similar to the rubber modified blends $[16,17]$. Of the $\mathrm{CaCO}_{3}$ composites the tensile set is also studied (Fig. 6).

The aPK-CaCO3 composites had TS values at strains 4$12 \%$ somewhat higher than that of the aPK with a maximum difference at 5-8\% strain. This suggests that the particle debonding has also an effect on the TS and the particle debonding is taking place well before the yield strain. The TS increases with $\mathrm{CaCO}_{3}$ content. The TS at $6 \%$ strain increases linearly with rubber and $\mathrm{CaCO}_{3}$ content (Fig. 7).

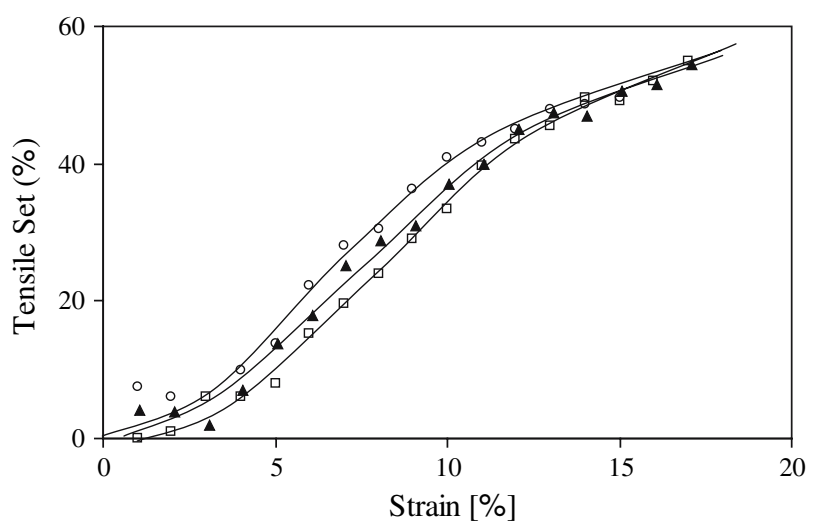

Fig. 6 Tensile set as function of strain of $\mathrm{aPK}-\mathrm{CaCO}_{3}$ composites: $\square$, aPK, $\boldsymbol{\Delta}, 16$ vol $\% \mathrm{CaCO}_{3} ; \bigcirc, 32$ vol\% $\mathrm{CaCO}_{3}$

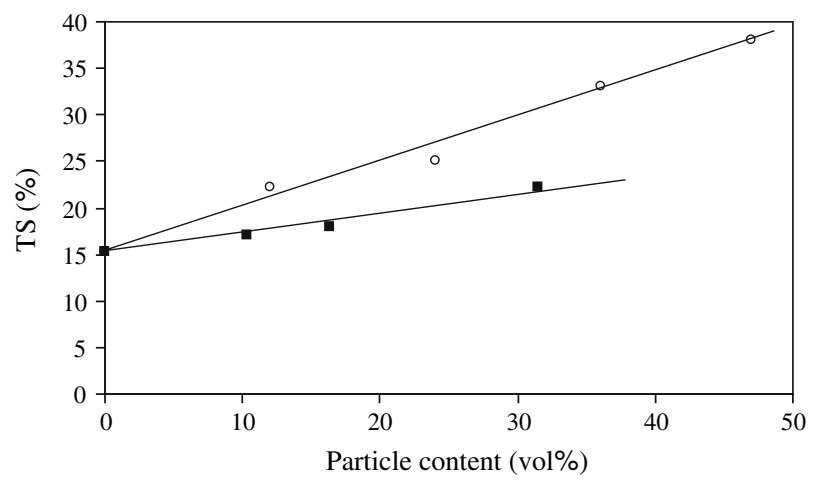

Fig. 7 Tensile set at $6 \%$ strain with particle content: $\bigcirc$, rubber; $\mathrm{CaCO}_{3}$

The 16 vol\% $\mathrm{CaCO}_{3}$ composite has a high toughness, however the 32 vol\% not. This difference of toughness behaviour cannot be explained by the TS results as the TS at high contents does not show unusual behaviour. The TS increases stronger for the rubber blend than for the $\mathrm{CaCO}_{3}$ composite. This suggests that the cavitation of the rubber is more effective in changing the deformation behaviour than the delamination of the $\mathrm{CaCO}_{3}$ particles. This TS method is a useful in studying the effects of cavitation in blends and delamination in composites on the deformation behavior.

\section{Conclusions}

Tensile set test with $1 \%$ strain steps gives interesting information about the deformation at low strains. Well before the yield point is reached, the tensile set values increases and at the same time the temperature of the sample increases. At the yield point a small change in tensile set was observed, and a $100 \%$ tensile set was observed at the drawing strain. During drawing the deformation is fully plastic. A blend of aPK-rubber cavitates on 
straining, with as a result an increase in plastic deformation. The onset of cavitation is at low strains and increasing the rubber content increases the plastic strain. $\mathrm{aPK}-\mathrm{CaCO}_{3}$ composites debond on straining with as a result a small increase in tensile set. This effect was strongest at $5-10 \%$ strain. The tensile set effects are stronger for the rubber blends than for the sub micron particles composites. The tensile set test is a sensitive method in studying the deformation processes at low strains.

Aknowledgements This research was financed by Shell Research and Technology Centre Amsterdam. The authors would like to thank P.J. Fennis and dr. A.A. Smaardijk for their contribution and helpful discussions.

\section{References}

1. Ferry JD (1980) In: Viscoelastic Properties of Polymers. Wiley \& Sons, NY

2. Kinloch AJ, Young RJ (1983) In: Fracture Behaviour of Polymers. Elsevier, London
3. Oleynik EF (1991) In: High Performance Polymers: Structure, Properties, Composites, Fibers. Hanser, Munich, p 79

4. Marshall I, Thompson AB (1954) Proc Roy Soc A 221:541

5. Müller FH (1952) Kolloidzeitschrift 126:65

6. Hookway DC (1958) J Text Inst 49:292

7. Van der Wal A, Gaymans RJ (1999) Polymer 40:6045

8. Zuiderduin WCJ, Homminga DS, Huétink HJ, Gaymans RJ (2003) Polymer 44:6361

9. Hiss R, Hobeika S, Lynn C, Strobl G (1999) Marcromolecules 32:4390

10. Hebeika S, Men Y, Strobl G (2000) Macromolecules 33:1827

11. Drozdov AD, Christiansen JD (2003) Macromol Mat \& Eng 288:164

12. Drozdov AD, Christiansen JD (2003) J Appl Polym Sci 88:1438

13. Zuiderduin WCJ, Vlasveld DPN, Huétink HJ, Gaymans RJ (2004) Polymer 45:3765

14. Barczak Z, Argon AS, Cohen RE, Weinberg M (1999) Polymer 40:2347

15. Kim GM, Michler GH (1998) Polymer 39:5689

16. Zuiderduin WCJ, Westzaan C, Huétink HJ, Gaymans RJ (2003) Polymer 44:261

17. Zuiderduin WCJ, Huétink HJ, Gaymans RJ (2006) Polymer 47:5880

18. Dijkstra K, Van der Wal A, Gaymans RJ (1994) J Mat Sci 29:3489 